\title{
Polyampholytic Poly(AEMA-co-SPMA) Thin Films and Their Potential for Antifouling Applications
}

\author{
Wetra Yandi, Bela Nagy, Andreas Skallberg, Kajsa Uvdal, Ralf Zimmermann, Bo Liedberg, \\ and Thomas Ederth*
}

Cite This: ACS Appl. Polym. Mater. 2021, 3, 5361-5372

Read Online

ACCESS | Llll Metrics \& More | 国 Article Recommendations ｜９） Supporting Information

ABSTRACT: Polyampholytic poly(2-aminoethyl methacrylate-co-sulfopropyl methacrylate) ( $\mathrm{p}$ (AEMA-co-SPMA)) thin films were prepared by self-initiated photopolymerization and photografting (SIPGP) and are demonstrated to be a potential alternative to films prepared from zwitterionic poly(sulfobetaine methacrylate) (pSBMA) for antifouling applications. SIPGP allows polymerization from aqueous solutions containing only monomers, implying that $\mathrm{p}$ (AEMA-coSPMA) thin films can be prepared simply and inexpensively without the risk of introducing potentially toxic substances necessary in many controlled polymer-

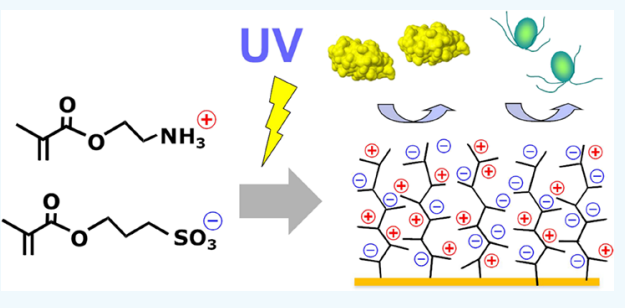
ization reactions. For the polymers, wettabilities were studied by contact angle goniometry, the compositions of the films were determined by infrared and X-ray photoelectron spectroscopies, and streaming current measurements were used to assess their net charge. The antibiofouling properties were compared via adsorption of fibrinogen and bovine serum albumin, settlement of algal zoospores, and the growth of sporelings of the marine alga Ulva lactuca. The fouling of the $\mathrm{p}$ (AEMA-co-SPMA) copolymer was in several respects similar to that of the zwitterionic pSBMA and suggests that it is potentially suitable for applications under high-salinity conditions, such as marine or physiological environments.

KEYWORDS: self-initiated photopolymerization and photografting, polyampholyte, poly(AEMA-co-SPMA), protein adsorption, marine biofouling, spore settlement, Ulva lactuca

\section{INTRODUCTION}

The need for robust, nontoxic, and environmentally benign antifouling coatings is increasing as biofouling problems in shipping and industrial aquatic processes remain unsolved, while broad-spectrum biocides are phased out due to environmental concerns or legislation. Biocide-free antifouling coatings relying on physicochemical methods to prevent or interfere with the processes preceding permanent attachment of the dispersal stage of marine organisms, that is, temporary attachment, settlement, or adhesion, require a good understanding of the mechanisms involved in the interactions between the organisms, or their adhesives, and man-made surfaces. As a result, research on suitable marine antifouling coatings is becoming more similar to related work in the biomedical field, where reliance on physicochemical means of prevention has been a necessity. In this context, understanding the charge interactions involved in biofouling processes is important since electrostatic interactions are involved in several early stages of fouling, irrespective of the application. This includes the adsorption of macromolecules forming a conditioning film on substrates, the interactions between the surface and the outer layer membrane surface of fouling organisms, or interactions with organic compounds such as proteins or peptidoglycans, which are released by fouling organisms prior to, or during, the settlement. The strategy to minimize the surface charges is thus promising to reduce the electrostatic component of any such interactions, which has also been explicitly investigated for protein adsorption. ${ }^{1}$ In practice, a charge-neutral surface is difficult to achieve since most surfaces spontaneously acquire a negative electrical charge when brought into contact with an aqueous medium, either by selective adsorption of ions or by dissociation of ionizable residues.

Zwitterionic materials consist of equal numbers of anionic and cationic ionizable residues. These materials have gained increasing attention due to their excellent antifouling properties $^{2,3}$ and their particular suitability for applications in biological systems. ${ }^{4}$ Studies on the application of zwitterionic materials include, for example, biomedicine, ${ }^{5}$ antibacterial coatings, ${ }^{6}$ biosensors, ${ }^{7}$ separation processes, ${ }^{8}$ and many other antifouling applications. ${ }^{9}$ Zwitterionic polymers are of particular interest for marine and biomedical antifouling coating applications, where the salinity is high, since their hydration is influenced by the environmental ionic strength. ${ }^{10}$ In contrast to other types of polyelectrolytes, the fouling

Received: March 22, 2021

Accepted: August 17, 2021

Published: September 30, 2021 
resistance of many zwitterionic materials increases as the ionic strength is increased due to the antipolyelectrolyte behavior; ${ }^{11}$ screening of the charges in the polymer reduces the electrostatic attraction between oppositely charged residues, causing chain expansion and swelling of the now strongly hydrated polymer chains. ${ }^{12}$ In practice, most zwitterionic polymers are prepared from a very limited number of zwitterionic monomers. ${ }^{3}$ Inspired by the structure of zwitterionic polymers, fouling-resistant materials can be prepared by mixing two oppositely charged monomers, thus keeping control over the charge neutrality. ${ }^{13}$ This also broadens the range of possible antifouling materials since there is a large number of positively and negatively charged monomers that can be employed to generate charge-neutral copolymer coatings, but avoiding the complications and additional costs involved in synthesizing zwitterionic monomers. The groups of Jiang, ${ }^{14}$ Chang, ${ }^{12}$ and others ${ }^{15}$ have successfully prepared zwitterionic-like, so-called pseudozwitterionic polymer brushes by controlling the balance between positive and negative residues using surface-initiated atomtransfer radical polymerization (SI-ATRP). These materials showed both low protein adsorption and blood cell attachment with potential applications in biosensors and in the biomedical field. A characteristic feature of many such systems is the antipolyelectrolyte behavior with increased swelling at higher ionic strength accompanied by increased resistance to fouling. ${ }^{10,12}$ This suggests that pseudozwitterionic materials could be well suited for use under conditions of high salinity, and in particular, for use in marine and physiological environments. Hitherto, most fouling studies of pseudozwitterionic materials have been conducted with biomedical applications in mind. ${ }^{12-14,16-19}$ For marine applications, zwitterionic materials have attracted considerable attention, covering assays using carboxybetaines, ${ }^{20,21}$ phosphorylcholines, ${ }^{22}$ and sulfobetaines. ${ }^{20-24}$ However, investigations of the potential of pseudozwitterionic materials for marine antifouling are so far limited. ${ }^{25}$

For practical applications, the ideal coating should be inexpensive and simple to prepare. Controlled polymerization methods such as atom-transfer radical polymerization (ATRP) or reversible addition/fragmentation chain transfer (RAFT) provide well-controlled synthesis but require specific atmospheric conditions as well as costly and potentially toxic chemicals (halide initiators, transition-metal ligands, or chaintransfer agents). In this study, we use a simple, rapid, low-cost method; self-initiated photopolymerization and photografting (SIPGP), for preparing polyampholytic thin hydrogel-like films. In SIPGP, no separate initiator is needed, but the monomers act also as initiators ("inimers" or initiator monomers). The monomers are excited by UV irradiation to form radicals with enough energy to initiate free-radical polymerization in the solution, but which might also abstract hydrogen atoms from the substrate to form surface-bound radicals as starting points for grafting. This is an uncontrolled polymerization reaction where polymerization proceeds in the bulk and monomers, oligomers, or polymers are grafted, while possibly also cross-linking and branching of grafted chains occur. $^{26,27}$ In previous studies in our lab, this preparation method has been used to fabricate both excellent antifouling coatings $^{28,29}$ and charge-balanced materials. ${ }^{30,31}$ Among the advantages of this method is that it is inexpensive and simple in setup and preparation, uses water as the solvent, and is compatible with a wide range of monomers, substrate surface chemistries (almost any organic material), ${ }^{32}$ and geometries. ${ }^{33}$ For use in sensitive environments and for biological assays, it also has a considerable advantage since it does not use initiators or catalysts, thus eliminating the risk of toxicity from residual chemicals, for example, $\mathrm{Cu}$ ions, and only the potential toxicity of remaining free monomers needs to be considered.

Here, we aim at preparing pseudozwitterionic thin polymer film coatings from 1:1 mixtures of cationic 2-aminoethyl methacrylate (AEMA) and anionic sulfopropyl methacrylate (SPMA) monomers and testing their antifouling properties. The performance is compared to homopolymers prepared from the two monomers as well as a regular zwitterionic sulfobetaine methacrylate (SBMA) polymer film prepared in a similar manner. We characterize the physicochemical properties of the coatings, and the antifouling performance is tested by protein (fibrinogen and bovine serum albumin) adsorption assays and via the settlement of zoospores and growth of sporelings of the marine green alga Ulva lactuca (U. lactuca).

\section{MATERIALS AND METHODS}

Materials. 2-aminoethyl methacrylate hydrochloride (AEMA), 3sulfopropyl methacrylate potassium salt (SPMA), [2(methacryloyloxy)ethyl]dimethyl-(3-sulfopropyl)-ammonium hydroxide (SBMA), fibrinogen, bovine serum albumin (BSA), and phosphate-buffered saline (PBS) tablets were purchased from Sigma-Aldrich Sweden $\mathrm{AB}$ and used as received. 11-Mercapto-1undecanol $\left(\mathrm{HS}-\left(\mathrm{CH}_{2}\right)_{11}-\mathrm{OH}\right)$ for preparation of $\mathrm{OH}$-terminated selfassembled monolayers (OH-SAMs) was purchased from ProChimia Surfaces, Poland. Spore settlement and sporeling growth experiments were carried out on cleanroom-cleaned Nexterion B, $26 \times 76 \times 1$ $\mathrm{mm}^{3}$, glass microscope slides (Schott AG, Germany) coated on one side. Artificial sea water (ASW) was prepared by dissolving $24.5 \mathrm{~g}$ of sodium chloride, $4.1 \mathrm{~g}$ of sodium sulfate, $11.1 \mathrm{~g}$ of magnesium chloride hexahydrate, $1.5 \mathrm{~g}$ of calcium chloride dihydrate, and $0.7 \mathrm{~g}$ of potassium chloride in $1 \mathrm{~L}$ of Milli- $\mathrm{Q}$ water (MQ Millipore, USA), adjusted to $\mathrm{pH} 8.2$ with $0.1 \mathrm{M} \mathrm{NaOH}$, and filtered through a $0.2 \mu \mathrm{m}$ pore size membrane filter (Nalgene, USA).

Preparation of OH-Terminated SAM Surfaces. Nexterion B glass slides were coated with a $25 \AA$ adhesion-promoting titanium layer and $300 \AA$ gold by electron-beam evaporation under vacuum. These gold-coated glass substrates were cleaned in a solution of $25 \%$ $\mathrm{NH}_{3}, 30 \% \mathrm{H}_{2} \mathrm{O}_{2}$, and Milli-Q water in a 1:1:5 ratio for $10 \mathrm{~min}$ at 85 ${ }^{\circ} \mathrm{C}$ (TL1 cleaning). After rinsing several times with Milli-Q water, the surfaces were blow-dried in $\mathrm{N}_{2}$ and immersed in a $50 \mu \mathrm{M}$ solution of mercaptoundecanol in ethanol for at least $24 \mathrm{~h}$ to form a monolayer. After 2 min of sonication and rinsing with ethanol, the OH SAMimmobilized gold substrates were blow-dried in $\mathrm{N}_{2}$ as described above before polymer grafting.

Preparation of Polymer Films. The thin polymer films were SIPGP-grafted from OH-SAMs, see Figure 1. Then, $5-10 \mu \mathrm{L} / \mathrm{cm}^{2}$ of 0.2-0.5 M monomer solution in Milli- $Q$ water was used for polymerization. The molar ratio of AEMA and SPMA was kept at $1: 1$ during the preparation of $\mathrm{p}$ (AEMA-co-SPMA) films. Large samples $\left(25 \times 75 \mathrm{~mm}^{2}\right.$ microscope slides $)$ for spore settlement and sporeling growth assays and samples for X-ray photoelectron spectroscopy (XPS) were prepared using $5 \mu \mathrm{L} / \mathrm{cm}^{2}$ of $0.2 \mathrm{M}$ monomer solutions. Samples for Fourier transform infrared reflection-absorption spectroscopy (FT-IRAS), wettability, and protein adsorption were prepared using both $5 \mu \mathrm{L} / \mathrm{cm}^{2}$ of $0.2 \mathrm{M}$ and $10 \mu \mathrm{L} / \mathrm{cm}^{2}$ of $0.5 \mathrm{M}$ monomer solutions. Samples for streaming current measurements were prepared using $10 \mu \mathrm{L} / \mathrm{cm}^{2}$ of $0.5 \mathrm{M}$ monomer solutions. For grafting, the monomer solution was placed on the OH-SAM substrate surface, and a transparent quartz disc was gently placed on top of this surface. The solution was then allowed to distribute evenly between the substrate and the quartz disc via capillary forces. The thickness of the liquid layer between the surfaces is approximately $40 \mu \mathrm{m}$. The assembly was irradiated by a UV light 
(a)

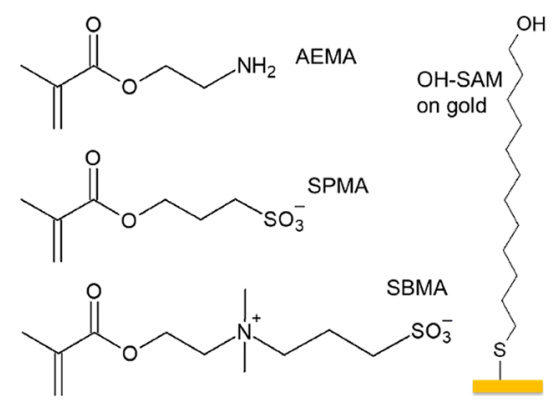

(b)

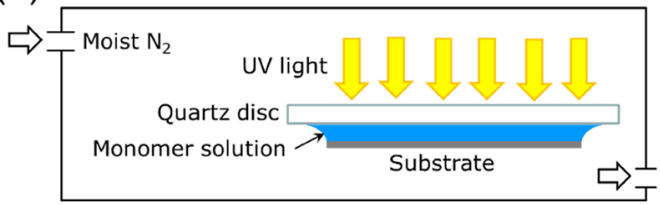

Figure 1. (a) Scheme of the three types of monomers used and the molecule forming the SAMs. (b) Outline of the reaction chamber.

using a Philips TUV PL-L lamp (18 W, main emission at $254 \mathrm{~nm}$ ), see Figure $1 \mathrm{~b}$. The irradiation time was varied to account for differences in the polymerization rate between the different monomer solutions and in general tuned to obtain dry thicknesses of 200-300 $\AA$. One minute before irradiation, and throughout the UV polymerization, the reaction chamber was purged with moist nitrogen gas to reduce interference of oxygen and evaporation of the solvent. Nitrogen was moisturized in a water-filled gas wash bottle immediately before entering the reaction chamber. After irradiation, samples were sonicated in Milli-Q water for 2 min followed by overnight immersion in water to remove unreacted monomers and other chemical residues. The samples were then blown dry and kept in sealed containers until further use. To test whether the collapse of the polymer due to the antipolyelectrolyte behavior prevents effective removal of residual monomers upon rinsing in Milli- $\mathrm{Q}$ water, rinsing in $500 \mathrm{mM} \mathrm{NaCl}$ was also tested, without any differences in film thicknesses. Thus, Milli- $Q$ rinsing was retained to minimize loading of ions into the polymer.

Polymer Characterization. The chemical structure of the polymers was investigated by FT-IRAS at a grazing incidence angle of $85^{\circ}$. The spectrometer (Bruker IFS66) was equipped with a liquid nitrogen-cooled mercury cadmium telluride detector. A deuterated hexadecanethiol $\left(\mathrm{HS}\left(\mathrm{CD}_{2}\right)_{15} \mathrm{CD}_{3}\right)$ SAM on gold was used to record the background spectrum. XPS analyses were performed using an Axis Ultra DLD spectrometer (Kratos Analytical, UK) using a monochromatized $\mathrm{Al}(\mathrm{K} \alpha)$ radiation with $1486.6 \mathrm{eV}$ photon energy. The background pressure during spectra acquisition was lower than $1 \times$ $10^{-9}$ mbar. The experimental conditions were such that the full width at half maximum of the silver $\mathrm{Ag}\left(3 \mathrm{~d}_{5 / 2}\right)$ line was $0.56 \mathrm{eV}$. The samples were analyzed in the as-received state, and the size of the analyzed area was $0.3 \times 0.7 \mathrm{~mm}^{2}$. The XPS spectra were referenced to the hydrocarbon $\mathrm{C}$ 1s signal at $285.0 \mathrm{eV}$. No surface charging was observed during the XPS analyses. The polymer film thicknesses were determined with a Rudolph Research Auto EL III ellipsometer (HeNe laser at $632.8 \mathrm{~nm}$ and $70^{\circ}$ incidence angle). The refractive index of gold (TL1-cleaned as previously described) was measured prior to polymer grafting and used for the substrate optical properties when calculating the polymer thicknesses. The thickness was calculated using a three-layer gold/polymer/air model with the refractive index of the polymer set to 1.5 . Wettabilities were assessed by advancing water contact angle measurements in air using a CAM 200 optical contact angle meter (KSV Instruments Ltd., Finland) equipped with a manual liquid dispenser. A video system with software for calculating contact angles was used to analyze images acquired during quasi-static expansion of a droplet placed on the surface.

Three water droplets were measured on each surface in their dry state, and for each droplet, 10 images were collected and both sides of the droplet were analyzed, giving 20 data points per droplet. Streaming current measurements were carried out at varying pressures (0-200 mbar) across rectangular channels (length: $20 \mathrm{~mm}$, width: 10 $\mathrm{mm}$, and height: $\sim 25 \mu \mathrm{m}$ ) formed by two identically coated sample carriers using a microslit electrokinetic setup. ${ }^{34-36}$

Protein Adsorption. Fibrinogen and BSA were used as models to assess the resistance to protein adsorption. The optical properties of each sample were determined by ellipsometry prior to the assays. After washing three times with PBS followed by immersion in PBS for $1 \mathrm{~h}$ to let the polymer layers swell, the samples were incubated in the protein solution $(0.4 \mathrm{mg} / \mathrm{mL})$ for $1 \mathrm{~h}$ at room temperature. After washing three times again with PBS, the samples were gently blowdried under a $\mathrm{N}_{2}$ stream, and the thickness was measured ellipsometrically to obtain the change in thickness due to the adsorbed proteins. As above, the thickness was calculated using a three-layer gold/organic layer/air model with the refractive index of the organic layer set to 1.5 . To ascertain that the observed changes in thicknesses were caused by the adsorbed proteins, FT-IRAS measurements were performed to verify the presence of proteins.

Settlement of Spores of the Marine Alga U. lactuca. The spore settlement assay was performed following a previously reported protocol. ${ }^{37}$ The reproductive plants of the marine alga U. lactuca were collected from a site $(588625 \mathrm{~N} ; 111308 \mathrm{E})$ near the Sven Lovén Centre for Marine Sciences, Tjärnö, Sweden. The motile spores were released, and the concentration was adjusted to $\mathrm{OD}_{600 \mathrm{~nm}}=0.1$ using filtered ASW. Three replicates of each sample were placed separately in polystyrene Quadriperm dishes (Greiner Bio-One Ltd.) and equilibrated in ASW for $1 \mathrm{~h}$ prior to the assay. After removing the ASW, $10 \mathrm{~mL}$ of the spore suspension was added to each well and incubated for $45 \mathrm{~min}$ in the dark. After washing with ASW, the samples were fixed in $10 \mathrm{~mL}$ of $2.5 \% \mathrm{w} / \mathrm{w}$ glutaraldehyde in ASW for $20 \mathrm{~min}$ at room temperature. The samples were then successively washed in ASW, ASW/deionized water (1:1 by volume), deionized water and then air-dried. The number of settled (adhered) spores was determined by chlorophyll $a$ autofluorescence using an epifluorescence microscope (20x objective; $\lambda$ excitation and emission of 546 and $590 \mathrm{~nm}$, respectively). A total of 30 images were captured on each sample slide at every $5 \mathrm{~mm}$ along three parallel rows.

Growth of Sporelings. After releasing the spores and letting the spores settle on the tested surfaces in the dark, as described above, 10 $\mathrm{mL}$ of an enriched seawater medium ${ }^{38}$ was added to each well and incubated at $23{ }^{\circ} \mathrm{C}$ with a $16 \mathrm{~h}: 8 \mathrm{~h} \mathrm{light} /$ dark cycle. The medium was refreshed after $24 \mathrm{~h}$ and then every 2 days. The sporelings were harvested by scraping with a razor blade after 3 or 8 days of incubation. Biomasses were determined by extraction of chlorophyll alpha (chlo a) in DMSO, and the amount of chlo $a$ present in the solution was determined using the Jeffrey and Humphrey method. ${ }^{39}$

Statistical Analysis. The adsorption of protein is presented as the thickness of the protein layer. Error bars represent the standard deviation from five measurements on each sample. Ulva spore settlement is presented as the number of settled spores per $\mathrm{mm}^{2}$ with $95 \%$ confidence limits. The sporeling growth on the polymer films is presented as the total sporeling biomass on the tested surfaces, as determined by the amount of chlo $a$. Error bars represent the standard deviation from three replicates of each sample.

Statistical analysis of the protein adsorption, spore settlement, and sporeling growth data was carried out using Minitab 16 statistical software and one-way analysis of variance (ANOVA) with $\alpha=5 \%$, and Tukey's HSD post hoc tests were performed to determine the difference between samples. Values were considered significantly different from each other when the $p$ value $(p)<0.05$.

\section{RESULTS AND DISCUSSION}

Polymer Preparation. In SIPGP, high-energy UV radiation excites monomers, forming radical species primarily through methacrylate double bond cleavage. This procedure initiates free-radical polymerization, and surface-bound radicals are formed via hydrogen abstraction from the surface, or from already grafted chains, assisted by the high energy of the UV 
radiation. The structure of the polymer is determined by a combination of steric constraints, radical stability (reactivity), and the diffusion rates of species from the solution. We expect that the formed polymer is heterogeneous, with grafts to the surface or existing polymers formed in many different ways.

While grafting to the surface could occur via hydrogen abstraction from the OH-SAM hydroxyl groups, it is also possible that exposed $\mathrm{C}-\mathrm{H}$ bonds upon degradation of the surface layer participate in grafting or that oxygen radicals abstract hydrogens from the methylene residues, transferring the radical down the chain. Thus, the coupling to the surface might produce both ether linkages and $\mathrm{C}-\mathrm{C}$ bonds. Similarly, hydrogens on the already grafted chains are also possible targets for grafting of polymers, oligomers, or monomers from the solution, resulting in chain branching. Aliphatic hydrogens are the most likely targets, but heteroatom effects are likely to direct these specifically to methylene residues adjacent to amines or ethers. We also note the possibility that radicals on already grafted residues react with each other, resulting in cross-linking and potentially in a hydrogel-like network structure.

The polymerization rate is strongly dependent on the monomer, with AEMA (and to some extent also SPMA) polymerizing much slower than the 1:1 mixture used to prepare the $\mathrm{p}$ (AEMA-co-SPMA) films and SBMA being intermediate in terms of the polymerization rate; see Table 1

Table 1. Preparation Parameters for the Polymer Thin Films Prepared with $10 \mu \mathrm{L} / \mathrm{cm}^{2}$ of $0.5 \mathrm{M}$ Monomer Solutions, Except for the Last p(AEMA-co-SPMA) Entry Where $1.5 \mu \mathrm{L} / \mathrm{cm}^{2}$ Was Used

\begin{tabular}{lccc}
\multicolumn{1}{c}{$\begin{array}{c}\text { illumination time } \\
(\mathrm{min})\end{array}$} & $\begin{array}{c}\text { thickness } \\
(\AA)\end{array}$ & $\begin{array}{c}\text { advancing contact } \\
\text { angles }\left(^{\circ}\right)\end{array}$ \\
pAEMA & 3 & $86 \pm 10$ & $68 \pm 10$ \\
pSPMA & 5 & $78 \pm 10$ & \\
& 3 & $175 \pm 7$ & $<10$ \\
p(AEMA-co- & 5 & $77 \pm 4$ & \\
SPMA) & 2 & $736 \pm 3$ & $58 \pm 2$ \\
$\left(\begin{array}{l}\text { using } 1.5 \mu \mathrm{L} / \\
\left.\mathrm{cm}^{2}\right)\end{array}\right.$ & 4 & $720 \pm 21$ & \\
pSBMA & 4 & $341 \pm 43$ & \\
& 3 & $211 \pm 9$ & $<10$ \\
& 5 & $203 \pm 6$ & \\
\hline
\end{tabular}

for thicknesses obtained at various UV illumination times. The lower polymerization rate of pAEMA is related to the lower solubility of AEMA compared to SPMA and SBMA (which is also indicated by the lower wettability of pAEMA by water, see Table 1). This slows down the polymerization process and results in layers with increased heterogeneity. It is also likely that unfavorable Coulomb interactions between monomers and the polymerized film reduce the growth rate for both pAEMA and PSPMA. The polymerization competes with continuous UV degradation of the polymer, which is an inevitable consequence of UV exposure ${ }^{28}$ resulting in a nonmonotonous relation between UV illumination time and polymer film thickness (see also Supporting Information Figure S1). In most cases, the dry film thickness decreases at exposure times beyond 3-4 min (Table 1), but even if the thickness does not change significantly upon additional exposure, it is possible that the degree of cross-linking or branching within the film changes as a result of the continuing UV irradiation. Infrared spectra of $\mathrm{p}$ (AEMA-co-SPMA) films with thicknesses in the range of 300-750 $\AA$ do not reveal significant differences when normalized to the carbonyl stretching vibration at $1734 \mathrm{~cm}^{-1}$ (see Figures S2 and S3), and the $\mathrm{C}-\mathrm{H}$ stretching bands are too weak to infer changes, and cannot support any conclusions regarding the degree of cross-linking. In addition, fibrinogen adsorption assays do not yield different results on samples with variations in thickness (see Figure S4), and we find it reasonable to assume that for our purposes, any variations in the polymer structure for the ranges of exposure times and thicknesses listed in Table 1 are small.

Comparing the obtained thicknesses with those obtained with other methods is difficult since it is not clear what would be comparable conditions. In our case, both the UV exposure and the geometric constraints limit the obtainable thicknesses (which are also, as discussed above, dependent on the monomer). We note that the literature on ATRP preparation of pSBMA reports thicknesses similar to ours ${ }^{40}$ but also pSPMA and pSBMA film thicknesses extending to several tens of micrometers. ${ }^{41}$

Contact angle measurements were conducted in air using deionized water to determine the wettabilities of the polymer films. Advancing contact angles for the four polymer types are reported in Table 1. Contact angles for the anionic pSPMA and the zwitterionic PSBMA polymers are very low, indicating strongly hydrophilic materials (angles $<10^{\circ}$ cannot be determined with any accuracy using goniometric methods). The contact angle for the cationic pAEMA was considerably higher, ca. $68^{\circ}$. Although pAEMA has a strong hydrophilic character due to hydration of the amine in contact with water, ${ }^{42}$ the polarity is apparently much less in its dehydrated form. The contact angle of $\mathrm{p}$ (AEMA-co-SPMA) falls between those of pAEMA and PSPMA, as expected for a mixture of the two components, but we emphasize that the contact angles as such cannot be used to infer quantitative information about the composition due to possible reorganization of the polymer at the interface in response to the properties of the interfacing medium. The difference in wettability between the copolymer $\mathrm{p}$ (AEMA-co-SPMA) and the proper zwitterionic pSBMA is notable, a result which could be explained by the greater flexibility of the copolymer, allowing for local separation of the strongly hydrophilic and the much less polar cationic residues near the interface. Upon immersion in water, and subsequent hydration of the charged residues, this difference is reduced. It is widely accepted that strongly hydrophilic surfaces bind water molecules tightly, resulting in, for example, reduced nonspecific protein adsorption and biofouling, but it has also been demonstrated that the ionic solvation of water molecules is stronger than the hydrogen bonding in hydrophilic polymers, ${ }^{43}$ and the properties of both materials are dominated by the hydration of the ionizable residues, once immersed in water.

Streaming Current Measurements. In order to assess whether charge neutrality was achieved on the p(AEMA-coSPMA) sample, streaming current measurements were performed and compared to the results obtained on the zwitterionic pSBMA sample. As the high salinities of both ASW and PBS, and the associated short Debye screening lengths, are not suitable for streaming current measurements, the total electrolyte concentrations had to be reduced for these measurements; the electrolyte conditions and the results are shown in Table 2.

Being aware of the fact that the hydrodynamic flow partially penetrates the soft surface layers at the walls of the streaming 
Table 2. Streaming Current Data and Apparent Zeta Potentials Calculated for p(AEMA-co-SPMA) and pSBMA Films

\begin{tabular}{|c|c|c|c|}
\hline & & $\begin{array}{l}\text { streaming current vs } \\
\text { pressure gradient ( } \mathrm{pA} / \\
\text { mbar) }\end{array}$ & $\begin{array}{c}\text { apparent zeta } \\
\text { potential }(\mathrm{mV})\end{array}$ \\
\hline \multirow[t]{2}{*}{$\begin{array}{l}\mathrm{p} \text { (AEMA- } \\
\text { co-SPMA) }\end{array}$} & $\begin{array}{c}10 \mathrm{mM} \\
\mathrm{NaCl} \\
\mathrm{pH} 8\end{array}$ & $-34.9 \pm 12.6$ & $-37.9 \pm 13.6$ \\
\hline & $\begin{array}{c}\text { 1/10 PBS, } \\
\text { pH } 7.4\end{array}$ & $-31.4 \pm 1.2$ & $-34.0 \pm 1.3$ \\
\hline \multirow[t]{2}{*}{ pSBMA } & $\begin{array}{l}10 \mathrm{mM} \\
\mathrm{NaCl} \\
\mathrm{pH} 8\end{array}$ & $-32.7 \pm 14.1$ & $-35.5 \pm 15.3$ \\
\hline & $\begin{array}{c}\text { 1/10 PBS, } \\
\mathrm{pH} 7.4\end{array}$ & $-18.2 \pm 4.1$ & $-19.8 \pm 4.5$ \\
\hline
\end{tabular}

channel, ${ }^{44}$ apparent zeta potentials were nevertheless calculated according to the Smoluchowski equation ${ }^{45}$ to make the obtained results better comparable with those for other surfaces (Table 2).

Neither of the two samples has apparent zeta potentials near zero, which would be expected from the molecular structure for at least a proper zwitterionic material. The negative excess charge detected by the streaming current measurements could be a result of additional charging mechanisms. Previous electrokinetic studies of zwitterionic phosphatidylcholine layers show consistent negative zeta potentials for these zwitterionic lipids at all $\mathrm{pH}$ values above $4 .^{46,47}$ This was rationalized as an effect of preferential adsorption of hydroxide ions at the interface. These observations are in agreement with observations of electrolyte-dependent sign and magnitude of the zeta potentials obtained on different sulfobetaine polyzwitterions ${ }^{48}$ and results obtained on pSBMA brushes, showing zeta potentials near $-40 \mathrm{mV}$ over a broad $\mathrm{pH}$ range. ${ }^{49}$ However, similar trends are observed on nominally charge-neutral surfaces such as thermoplastic polymers, ${ }^{50}$ methyl-terminated SAMs, ${ }^{51}$ and oil-water interfaces, ${ }^{52}$ which are also charged by preferential adsorption of ions from the aqueous bulk, suggesting that the observed negative zeta potentials are the manifestation of a general phenomenon, rather than a result of the specific materials used in this study. Considering that in our case, both tested samples have negative apparent zeta potentials, we hypothesize that a similar hydroxide ionadsorption mechanism can explain the data for both polymer types. We conclude that streaming current measurements alone do not allow us to determine the ratio of anionic to cationic residues in the polymer films, and further, that this type of measurement cannot be easily applied to verify charge neutrality for (pseudo)zwitterionic polymers.

FT-IRAS Characterization. The chemical compositions of pAEMA, pSPMA, pSBMA, and p(AEMA-co-SPMA) films were evaluated by FT-IRAS, and the result is shown in Figure 2. Overall, the presence of the ester carbonyl $(\mathrm{C}=\mathrm{O})$ stretching around $1734-1730 \mathrm{~cm}^{-1}$ in all the spectra reflects the successful grafting of methacrylate monomers to the surfaces, and the absence of methacrylate $\mathrm{C}=\mathrm{C}$ bands at $1640 \mathrm{~cm}^{-1}$ indicates that very few, or no, free monomers remain in the films. The spectra for pSPMA and pSBMA lack features near this position, while any such bands would partially overlap with the $\mathrm{N}-\mathrm{H}$ bending observed at $1635 \mathrm{~cm}^{-1}$ in pAEMA and at $1631 \mathrm{~cm}^{-1}$ in $\mathrm{p}$ (AEMA-co-SPMA). However, close-ups of these bands do not indicate that any of these bands are bimodal (not shown). In pSPMA, pSBMA, and p(AEMA-co-

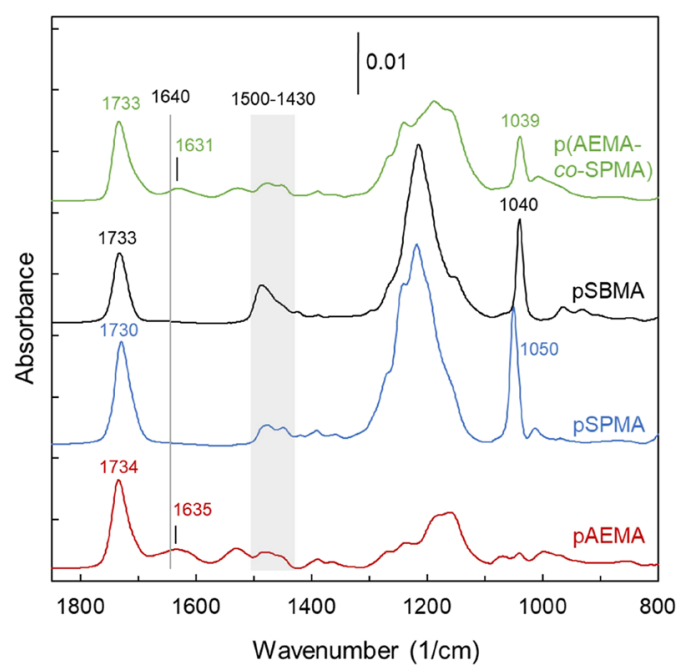

Figure 2. Infrared reflection-absorption spectra of the polymer films in the fingerprint region. See text for details on peak assignments.

SPMA), the symmetric $\mathrm{S}=\mathrm{O}$ stretching is characteristic and easily distinguishable at approximately $1050-1040 \mathrm{~cm}^{-1}$. Interestingly, the location of this band is slightly different for pSPMA $\left(1050 \mathrm{~cm}^{-1}\right)$ and pSBMA $\left(1040 \mathrm{~cm}^{-1}\right)$, but for $\mathrm{p}$ (AEMA-co-SPMA), the position at $1039 \mathrm{~cm}^{-1}$ is nearer the corresponding peak position in pSBMA than in pSPMA. The reason for this shift is the interaction of the sulfonates with the cationic ammonium residues in the copolymer (and in the zwitterionic film) that is not possible in the pSPMA homopolymer (as is also observed by XPS, see below). The broad bands in the range of $1300-1100 \mathrm{~cm}^{-1}$ are combinations of asymmetric $\mathrm{S}=\mathrm{O}$ and ether bond $\mathrm{C}-\mathrm{O}-\mathrm{C}$ stretching vibrations (though the former contribution is absent in PAEMA), for which detailed analysis would be superfluous for the present purpose. Similarly, the $\mathrm{C}-\mathrm{H}$ deformation modes in the range of 1500-1440 are expected, but their resolution is beyond the scope of the current analysis. Taken together, these results indicate that the four polymer types were successfully polymerized onto the substrates. Unfortunately, many infrared amine bands are weak and not suitable for quantitative analysis. The following XPS analysis is included to quantitatively describe the chemical composition of the films.

XPS Measurements. XPS measurements were performed to investigate the chemical compositions for three polymer films, pAEMA, pSPMA, and p(AEMA-co-SPMA), and specifically to confirm the presence of the two components in the $\mathrm{p}$ (AEMA-co-SPMA) copolymer. The XPS measurements include identification of chemical states and estimation of relative ratios with a focus on the chemical states of nitrogen and sulfur elements in the films. The XPS survey spectra are shown in Figure 3 for pAEMA, pSPMA, and p(AEMA-coSPMA). The XPS survey spectra for all three polymer samples showed presence of $\mathrm{O}$ and $\mathrm{C}$, with dominating peaks (e.g., $\mathrm{C}$ $1 \mathrm{~s}$ at about $285 \mathrm{eV}$ and $\mathrm{O} 1 \mathrm{~s}$ at about $532 \mathrm{eV}$ ) in good agreement with the composition of the polymer backbones of pAEMA, pSPMA, and p(AEMA-co-SPMA). ${ }^{53}$

The survey spectrum of pAEMA showed one peak at about $400 \mathrm{eV}(\mathrm{N} \mathrm{1s})$ that corresponds to the presence of nitrogen and two peaks at $269 \mathrm{eV}(\mathrm{Cl} \mathrm{2s})$ and $198 \mathrm{eV}(\mathrm{Cl} \mathrm{2p})$, indicating the presence of chlorine as the polyelectrolyte counterion. The PSPMA survey spectrum also showed a clear 


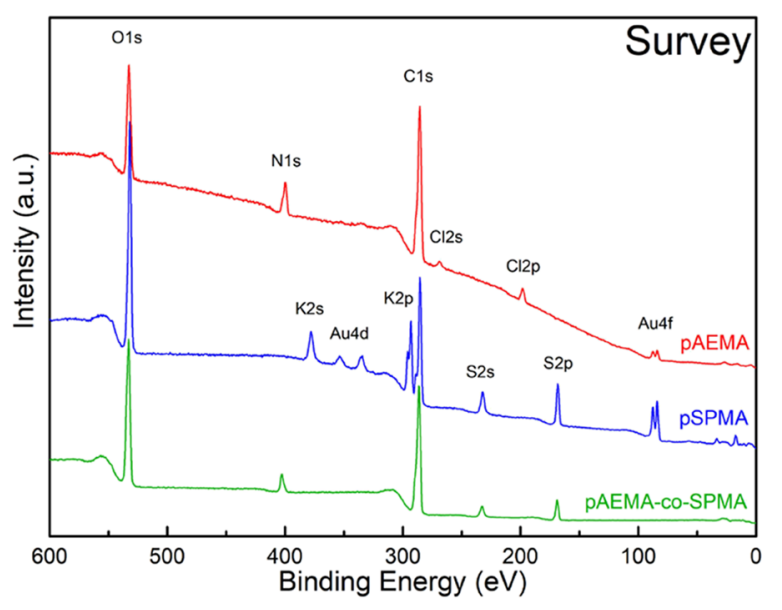

Figure 3. XPS survey spectra for pAEMA, pSPMA, and p(AEMA-coSPMA).

signal from sulfur at $231 \mathrm{eV}(\mathrm{S} 2 \mathrm{~s})$ and $168 \mathrm{eV}$ (S 2p) as well as the presence of potassium at $378 \mathrm{eV}(\mathrm{K} 2 \mathrm{~s})$ and $293 \mathrm{eV}(\mathrm{K}$ $2 \mathrm{p})$, consistent with the chemical ionic structure of the polymer. The elemental composition in at. \% and stoichiometric and experimental values for pAEMA, pSPMA, and p(AEMA-co-SPMA) are summarized in Table S1. Interestingly, for the copolymer $\mathrm{p}$ (AEMA-co-SPMA), the signals from both the counterions $\mathrm{K}$ and $\mathrm{Cl}$ were suppressed and the signals from $\mathrm{N}$ and $\mathrm{S}$ remain, which indicates that when the two polymers are mixed, they appear to charge-neutralize each other and expel the counterions. A possible reason for the retention of counterions in the PAEMA and PSPMA films is incomplete dissociation of ionizable residues upon rinsing due to the unfavorable electrostatic interactions of the remaining ionized moiety with surrounding charged residues and thus counterions remain in the film to reduce the repulsive Coulomb interactions. For the copolymer film, there are ionizable (and ionized) residues of the opposite charge in the polymer and hence the enthalpic barrier to dissociation and removal of the counterions is much lower. The extensive rinsing and soaking of the films during preparation facilitate removal of the counterions. This conclusion is further supported by the narrow scans on sulfur and nitrogen, Figure 4. The ratio of pAEMA to PSPMA in the copolymer was determined from the
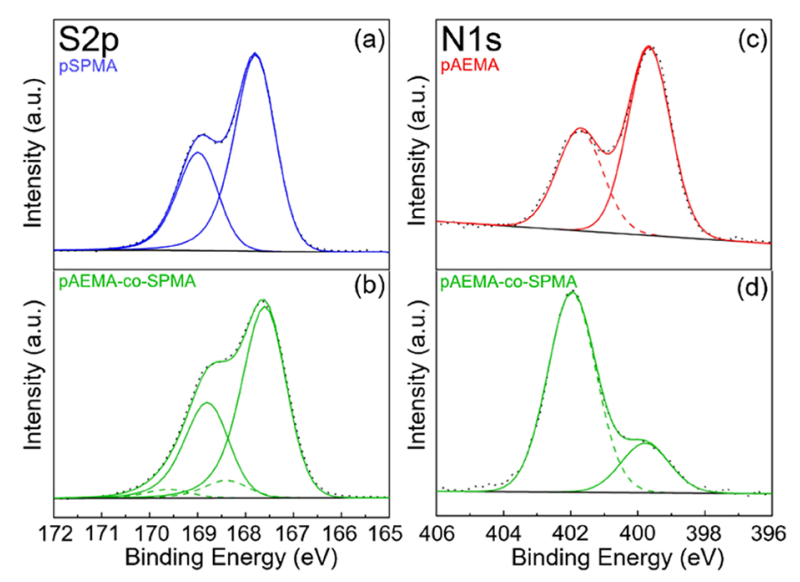

Figure 4. (a) $S 2 p$ core-level XPS spectra for pSPMA and (b) $\mathrm{p}$ (AEMA-co-SPMA). (c) N 1s core-level XPS spectra for PAEMA and (d) p(AEMA-co-SPMA). relative concentrations of $\mathrm{N}$ and $\mathrm{S}$ (from $\mathrm{N} 1 \mathrm{~s}$ and $\mathrm{S} 2 \mathrm{p}$ ) in $\mathrm{p}$ (AEMA-co-SPMA) and was calculated using sensitivity factorcorrected photoelectron peak areas, which yield an N/S atomic ratio of 0.85 . Thus, the copolymerization of pSPMA and pAEMA resulted in a polymer with nearly equal amounts of each component. The slight deficiency of AEMA in the film could be a result of the lower solubility of AEMA, differences in the degree of ionization of the two monomers, or degradation under the UV irradiation to which AEMA is more susceptible than SPMA. It is often observed during the preparation of, for example, pseudozwitterionic SAMs that the surface composition is insensitive to variations in the solution composition over a wide range of mixing ratios of the anionic and cationic components. ${ }^{54,55}$ This is attributed to electrostatic association of the two components in the solution during SAM formation, effectively pairing the ions before surface attachment. Nevertheless, it is clear that there are possibilities to tune the composition of a polyampholytic copolymer film via variations in the monomer ratios, especially if weak acids or bases are used for the preparation, for which ionization may be only partial. ${ }^{56,57}$ This implies that other parameters than charge will affect the composition of the copolymer film, perhaps diffusion rates and steric hindrance, in addition to the degree of ionization.

High-resolution XPS S 2p core-level spectra for pSPMA and $\mathrm{p}$ (AEMA-co-SPMA) and high-resolution XPS N 1s core-level spectra for pAEMA and p(AEMA-co-SPMA) are shown in Figure 4. The XPS S 2p spectra for pSPMA were deconvoluted into one double peak at binding energy positions of 167.8 and $168.9 \mathrm{eV}$ due to spin-orbit splitting, that is, $S 2 \mathrm{p}_{3 / 2}$ and $\mathrm{S}$ $2 \mathrm{p}_{1 / 2}$, respectively. The strong double peak is assigned to $-\mathrm{SO}_{3}{ }^{-} \mathrm{K}^{+}$species and a small amount of $\mathrm{SO}_{2} \cdot{ }^{58}$ The XPS S $2 \mathrm{p}$ spectra for $\mathrm{p}$ (AEMA-co-SPMA) have a double peak at a binding energy position of $167.6 \mathrm{eV}$ dominating the spectra, with a smaller contribution from a low-intensity double peak found at $168.6 \mathrm{eV}$. There is broadening of the $\mathrm{S} 2 \mathrm{p}$ spectra for $\mathrm{p}$ (AEMA-co-SPMA) compared to the PSPMA spectra, and the deconvoluted peaks are shifted by $0.2-0.3 \mathrm{eV}$. Since no signal from $\mathrm{K}$ or $\mathrm{Cl}$ in the survey spectra can be detected, the shift of the high-intensity peak at $167.6 \mathrm{eV}$ is assigned to $\mathrm{S} 2 \mathrm{p}_{3 / 2}$ in $-\mathrm{SO}_{3}{ }^{-}$interacting with $\mathrm{NH}_{3}{ }^{+}$and a small amount of $\mathrm{SO}_{2}{ }^{59,60}$ The low-intensity doublet with a peak position found at 168.6 $\mathrm{eV}$ is suggested to be contaminants such as oxidized sulfur species, $\mathrm{SO}_{x}$. The $\mathrm{S} 2 \mathrm{p}$ binding energy peak positions for the gold-sulfur bonds at the bottom of the SAMs are expected at about $162-163 \mathrm{eV},{ }^{61}$ and any contribution from these sulfur atoms is expected to be marginal because of the extensive attenuation of the corresponding photoelectrons within the polymer films.

The XPS N 1s core-level spectra were deconvoluted into two components. For pAEMA (Figure 4c), the deconvoluted peaks are present at binding energies of 399.6 and $401.7 \mathrm{eV}$. These two peaks are assigned to $-\mathrm{NH}_{2}$ and $-\mathrm{NH}_{3}{ }^{+} \mathrm{Cl}^{-}$, respectively. ${ }^{62}$ The relative intensities of these peaks contribute to $65 \%\left(-\mathrm{NH}_{2}\right)$ and $35 \%\left(-\mathrm{NH}_{3}{ }^{+} \mathrm{Cl}^{-}\right)$of the total $\mathrm{N}$ 1s intensity. When copolymerized, p(AEMA-co-SPMA) (Figure $4 \mathrm{~d})$, the deconvoluted peaks appear at binding energy positions of 399.6 and $401.8 \mathrm{eV}$. These peaks are similarly assigned to $-\mathrm{NH}_{2}$ and $-\mathrm{NH}_{3}{ }^{+} \mathrm{SO}_{3}{ }^{-}$, respectively. The relative atomic ratios for these two peaks are $19 \%\left(-\mathrm{NH}_{2}\right)$ and $81 \%$ $\left(-\mathrm{NH}_{3}{ }^{+} \mathrm{SO}_{3}{ }^{-}\right)$. When pAEMA is copolymerized with pSPMA, the atomic ratios for the assigned peaks are clearly changed compared to those in PAEMA. The peak found at 
$399.6 \mathrm{eV}$ decreased from 65 to $19 \%$, whereas the peak at about 401.7-401.8 eV increased from 35 to $81 \%$. A comparison with the survey scan, where no signal from $\mathrm{K}$ or $\mathrm{Cl}$ could be detected for $\mathrm{p}$ (AEMA-co-SPMA), suggests that the highintensity peak positioned at $401.8 \mathrm{eV}$ is due to interactions between $-\mathrm{NH}_{3}{ }^{+}$and $-\mathrm{SO}_{3}{ }^{-}$in the copolymer, which is in good agreement with the IRAS data. The $-\mathrm{NH}_{2}$ component drastically decreased when copolymerized with pSPMA, but some $-\mathrm{NH}_{2}$ was still present. The experimental values for $\mathrm{p}$ (AEMA-co-SPMA) show that we have more $S$ compared to $\mathrm{O}$, which suggests that we have not only $\mathrm{NH}_{3}{ }^{+} \mathrm{SO}_{3}{ }^{-}$but also $\mathrm{SO}_{2}$ species in the copolymer. We suggest that $\mathrm{SO}_{2}$ might have been derived from $\mathrm{SO}_{3}{ }^{-}$ions (or sulfite radicals) formed during photolysis of SPMA and their condensation to $\mathrm{SO}_{2}$. Overall, these observations are in good agreement with our quantification data analysis where the $\mathrm{N}$ to $\mathrm{S}$ ratio is 0.85 .

Protein Adsorption. Understanding the interactions between surfaces and biomolecules, such as proteins, is of considerable interest for coating development in many fields, notably biomedical and food industries, as well as in marine biofouling. The adsorption of proteins is typically the result of complex interactions including van der Waals and electrostatic interactions, hydrogen bonding, and hydrophobic interactions. The presence of proteins or other biomolecules on a surface might affect the attachment of fouling organisms or provide preferable conditions for microbial attachment and subsequent biofilm formation. We have used fibrinogen and BSA as models for protein adsorption assays. Fibrinogen is a well-established model and "sticky" protein that is often used to investigate resistance to nonspecific protein adsorption. The results for the protein adsorption assays are shown in Figure 5. The amount

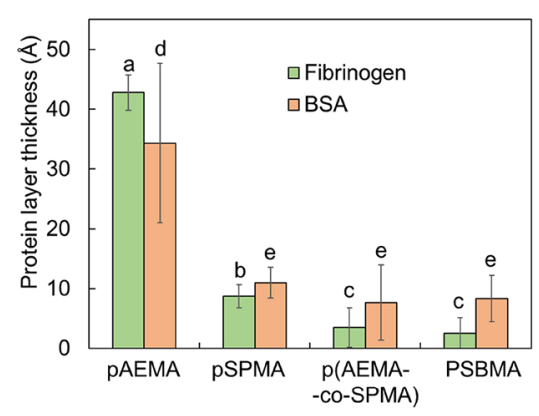

Figure 5. Adsorption of fibrinogen and BSA onto the polymers. The error bars represent the standard deviation (SD) from five measurements on each sample and data from four (fibrinogen) or three (BSA) different assays. Letters $(\mathrm{a}-\mathrm{e})$ indicate data points that do not differ significantly from each other at $p<0.05$ (ANOVA, Tukey's pairwise comparison).

of fibrinogen adsorbed on the polyampholytic p(AEMA-coSPMA) sample is significantly lower (ANOVA, Tukey's test, $p$ $<0.05)$ than those on pAEMA or pSPMA. These results show that combining AEMA and SPMA into an ampholytic polymer improves the antifouling properties of both pAEMA and pSPMA with protein resistance performance similar to that of the zwitterionic pSBMA. This is in accordance with a previous study that demonstrated that a 1:1 composition of charged residues is optimal and improves antifouling properties over that of homopolymers. ${ }^{56,57}$ BSA is also a commonly used model for protein adsorption and is frequently used for passivation of surfaces, preventing further (or other) adsorption and also reducing platelet adhesion. The results for BSA adsorption shown in Figure 5 show that beyond the much higher adsorption to pAEMA, as a result of the overall negative charge of BSA at physiological conditions, there are no significant differences in the adsorbed amount between the remaining three polymers.

To further verify the protein adsorption results and to obtain qualitative data for adsorption, samples were subjected to FTIRAS measurements before and after adsorption of fibrinogen and BSA, respectively, see Figure 6. Adsorbed proteins were
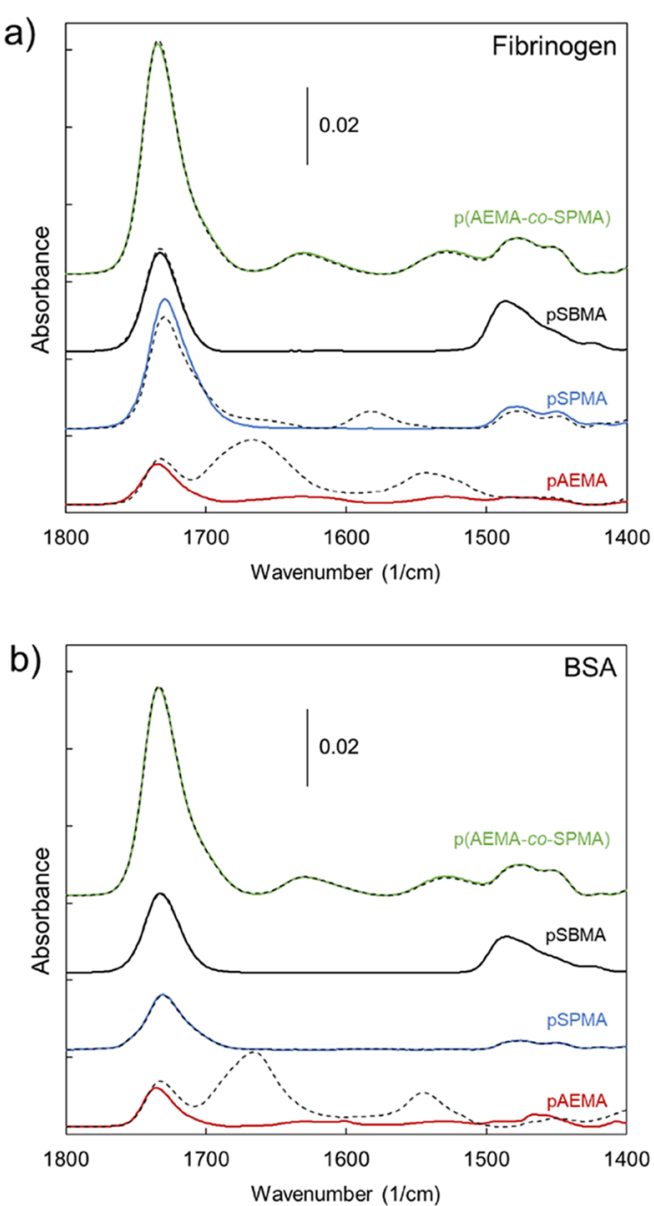

Figure 6. Infrared spectra covering the amide band region for the four polymers before (solid lines) and after (dashed lines) (a) fibrinogen and (b) BSA adsorption assays.

identified via the amide I $\left(1700-1600 \mathrm{~cm}^{-1}\right)$ and amide II (1600-1500 $\mathrm{cm}^{-1}$ ) bands, and to some extent, also via interactions with the carbonyl residues in the polymer, inducing intensity or peak position changes in the carbonyl peak at $1730 \mathrm{~cm}^{-1}$. The spectra confirm the trend observed in Figure 5, where adsorption, as determined via the intensities of the amide bands, is greatest on the pAEMA sample, lower on pSPMA, and lowest on P(AEMA-co-SPMA) and pSBMA, with very little changes in the spectra of the latter two.

Ulva Spore Settlement and Sporeling Growth. The marine green alga Ulva constitutes a class of major biofouling organisms, populating shores and man-made structures around the world. Reproductive Ulva plants produce vast amounts of microscopic motile swimming spores, which disperse to find new surfaces to settle onto. ${ }^{63}$ The spores have four flagella acting as locomotive and sensory organelles. Once committed to settlement, the permanently attached spores will germinate 
into young plants, so-called sporelings, within the next few days. The algal assays were conducted with $U$. lactuca zoospores. The result of the settlement assay is shown in Figure 7. Spore settlement differed significantly between

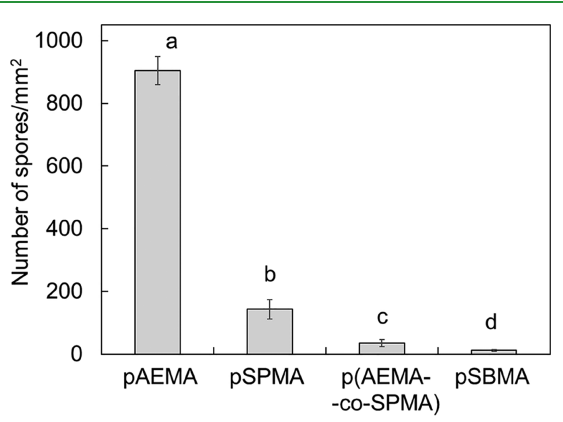

Figure 7. Settlement of zoospores of U. lactuca on cationic pAEMA, anionic pSPMA, polyampholytic p(AEMA-co-SPMA), and zwitterionic pSBMA. Error bars represent the SD. Letters $(a-d)$ indicate data points that do not differ significantly from each other at $p<0.05$ (ANOVA, Tukey's pairwise comparison).

samples (ANOVA, $p<0.05$ ). Post hoc pairwise Tukey comparisons show that the spore settlement was significantly lower $(p<0.05)$ on $\mathrm{p}$ (AEMA-co-SPMA) than on pAEMA or pSPMA (Figure 7). However, although total settlement onto both the charge-balanced surfaces $\mathrm{p}$ (AEMA-co-SPMA) and pSBMA was low, settlement was significantly higher (Tukey's test, $p<0.05)$ on the former surface $(35 \pm 11$ versus $12 \pm 3$ spores $/ \mathrm{mm}^{2}$ ). The low settlement is in good agreement with the published results obtained on pSBMA surfaces using other Ulva species. ${ }^{23,35}$ The massive settlement onto the pAEMA sample is most likely a result of electrostatic interactions. Ulva spores do not have a cell wall but expose a "bare" membrane, which is negatively charged (zeta potential is $-19 \mathrm{mV}$ for $U$. linza), ${ }^{64}$ suggesting that the massive settlement onto the cationic pAEMA surface is induced by attractive electrostatic interactions, in agreement with previous studies. ${ }^{35,65-67}$ Normally, the settled spores have a round shape, and upon a closer examination of spores settled on the pAEMA surface, a smaller fraction of pear-shaped spores was also observed (not shown). These "pseudosettled" spores are likely electrostatically trapped to the surface but do not undergo the morphological transformations associated with settlement. $35,65,68$ To the extent the Ulva spores are killed by the cationic surface, they remain on the surface as disrupted spores $^{68}$ and the low settlement onto p(AEMA-co-SPMA) and pSBMA is thus unlikely to be a result of surface toxicity, in agreement with data for pseudozwitterionic $\mathrm{SAMs}^{55}$ and toxicity tests with pSBMA. ${ }^{23}$

In addition to spore settlement, the growth of sporelings of U. lactuca was also studied. The sporeling biomass was assessed after 3 and 8 days of incubation in an enriched seawater medium. At 3 days of incubation, the biomasses on the samples were found to differ significantly from each other (ANOVA, $p$ $<0.05$ ), and pairwise comparisons (Tukey's tests) show that the mass on the copolymer $\mathrm{p}$ (AEMA-co-SPMA) is significantly lower $(p<0.05)$ than on PAEMA, not significantly different from the biomass on pSPMA $(p>0.05)$, but significantly higher than that on pSBMA $(p<0.05)$ (Figure $8 \mathrm{a})$. However, after 8 days of incubation, the biomasses on p(AEMA-coSPMA) and PSBMA were significantly lower than on the other two samples $(p<0.05)$ but not significantly different from (a)
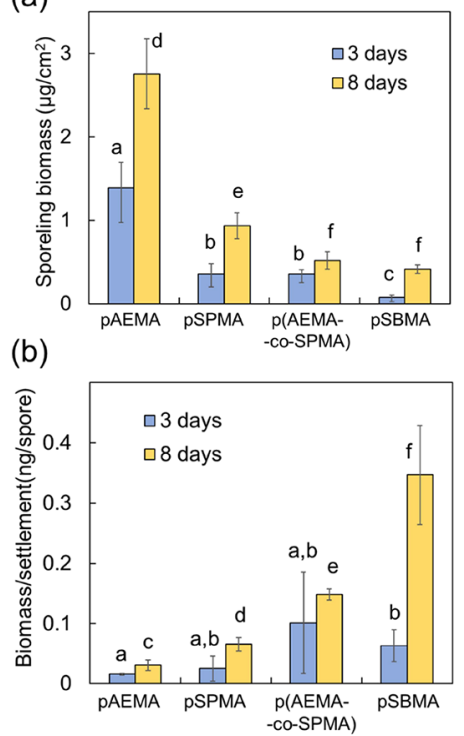

Figure 8. (a) Sporeling biomass of U. lactuca measured after 3 and 8 days of incubation in an enriched algal culture medium at $23{ }^{\circ} \mathrm{C}$. The error bars represent the SD from three measurements on each sample. Letters $(\mathrm{a}-\mathrm{f})$ indicate data points that do not differ significantly from each other at $p<0.05$ (ANOVA, Tukey's pairwise comparison). (b) Sporeling biomass data after being normalized to the spore settlement density data shown in Figure 7. The error bars represent the SD from three measurements on each sample. Letters $(a-f)$ indicate data points that do not differ significantly from each other at $p<0.05$ (ANOVA, Tukey's pairwise comparison).

each other $(p>0.05)$. The large biomass found on pAEMA, which is much higher than on the other samples $(p<0.05)$, is probably related to the large number of initially settled spores.

The widely different results for the settlement make the direct comparison of the sporeling biomass data difficult. Hence, it is also of interest to consider the biomass normalized to the settlement since this is a measure of the growth rate of the sporelings and removes the bias of the different settled amounts on different samples. These data are shown in Figure 8 b. In this graph, the mean sporeling biomasses are significantly different (ANOVA, $p<0.05$ ) and are lowest on pAEMA (Tukey's test, $p<0.05$ ), indicating slow growth, or phrased differently, effective growth inhibition. This is in agreement with a recent study where the antialgal properties of a similar cationic polymer (poly(2-(dimethylamino)ethyl methacrylate)) was discussed. ${ }^{68}$ Normalization shows that although pSBMA had the lowest absolute biomass after 3 days, it had by far the largest (Tukey's test, $p<0.05$ ) normalized biomass after 8 days, indicating that the copolymer $\mathrm{p}$ (AEMAco-SPMA) has a better inhibitory effect on algal growth than pSBMA.

UV Polymerization of Polyampholytes as an Alternative to Controlled Polymerization of Zwitterionic Polymers. The antibiofouling performance of zwitterionic polymers is well documented, but these materials are yet to find their way to large-scale applications. Zwitterionic monomers are expensive and inflexible, and it is likely that many practical antifouling coatings would benefit from, or indeed require, less costly options. Using separate anionic and cationic monomers to prepare pseudozwitterionic polymers vastly broadens the range of possible charge-balanced materials. A recurring problem in the preparation of 
copolymers is the control of the monomer ratio, and especially in cases where the monomer conversion or reactivity ratios are different for the involved monomers. With oppositely charged monomers, it is conceived that the Coulomb attraction between ionizable monomer pairs promotes alteration of the monomers during polymerization, as it has been observed in the formation of mixed SAMs, ${ }^{69}$ and facilitates the formation of a charge-balanced, zwitterion-like polymer. However, our XPS data indicate a 1:0.85 ratio of the monomers in the polymer film prepared from a 1:1 monomer ratio solution. Similarly, in a recent study, Sponchioni et al. found that copolymerization of sulfopropyl- and trimethylammoniumfunctionalized monomers at a 1:1 ratio resulted in imperfect charge alteration along the polymer chain, ${ }^{70}$ and an earlier study by Dobbins et al. made similar observations. ${ }^{13}$ It should also be mentioned that our copolymer is not a direct division of polysulfobetaine to its respective ionizable monomers; the quaternary ammonium, which is a strong cation, in our system is replaced by a primary amine whose degree of ionization is $\mathrm{pH}$-dependent. However, our results demonstrate that, for practical purposes, this is not necessarily a problem since fouling resistance at a level similar to a proper zwitterionic polymer is still retained even at monomer ratios deviating from $1: 1$.

A major benefit of the presented preparation method, in addition to the antifouling properties, is the low cost compared to many controlled radical polymerization processes. The latter often require costly chemicals beyond the monomers, often need a controlled (oxygen-free) atmosphere and associated infrastructure such as glove boxes, and also use vastly more reagents. Separate anionic and cationic monomers are often much less costly than the corresponding combined zwitterionic polymer, and the samples prepared in this study require monomer volumes of the order of $\mu \mathrm{L} / \mathrm{cm}^{2}$, while ATRP and RAFT grafting protocols frequently include volumes of the order of $\mathrm{mL} / \mathrm{cm}^{2}$, while still using similar monomer concentrations in the $\sim 1 \mathrm{M}$ range. This corresponds to an approximately 100 - to 1000 -fold difference in the amount of the used materials. In addition, controlled polymerization grafting times are typically several hours, sometimes extending to a day, whereas our samples are prepared in a few minutes.

For biological or biomedical applications, even trace amounts of the halide initiators, ligands, transition-metal catalysts, chain-transfer agents, or nonaqueous solvents that are used in many controlled radical polymerization methods are potentially toxic. With the presented method, using water as a solvent for the monomers, only the potential toxicity of the monomers needs to be considered. This, however, is not negligible for cationic monomers, but these are present in either case.

Here, the investigated polymers were prepared on goldcoated slides (with alkylthiol SAMs) for the purpose of detailed FT-IRAS and ellipsometric characterizations, but in the past, we have demonstrated that the same preparation method, which was carried out in the presence of only an aqueous solution of the monomers, can be used to prepare fouling-resistant polymer coatings on most organic materials ${ }^{32}$ and also in varying geometries. ${ }^{33}$ Despite the weaker control of both the polymerization process and the monomer ratio, this method results in efficient antifouling coatings, and the simplicity and flexibility with regard to substrates offered by this UV polymerization process further reduce the costs and barriers to practical applications. As with all antifouling coatings, for marine applications, future field test studies extending over several months are required to verify their practical utility and stability, using other more practically applicable substrates to support these polymers.

\section{CONCLUSIONS}

A polyampholytic $\mathrm{p}$ (AEMA-co-SPMA) polymer film was successfully prepared via SIPGP. The ratio of the cationic AEMA to the anionic SPMA monomers was estimated to be 0.85 by XPS in the copolymer, indicating a nearly equal amount of both monomers. A major benefit of a pseudozwitterionic polymer over a zwitterionic polymer is the greater flexibility in preparation of the polymer in which anionic and cationic monomers can be combined, giving great flexibility at a low cost. In fouling assays, the p(AEMA-coSPMA) copolymer showed both lower adsorption of proteins, lower settlement of Ulva zoospores, and lower sporeling biomass after 8 days, compared to the homopolymers pAEMA and pSPMA. The performance of the p(AEMA-co-SPMA) copolymer was comparable to that of the proper zwitterionic polymer PSBMA in the protein assay, somewhat inferior in the algal settlement assay, but again similar in the sporeling growth assay after 8 days. The polyampholytic p(AEMA-co-SPMA) copolymer, however, shows significantly better sporeling growth inhibition than pSBMA after 8 days. Physicochemical characterization shows that the copolymer contains hydration water and forms a strongly hydrated barrier, acting both as a physical and an energetic barrier to adhesion or attachment of proteins or spores approaching the surface. These results show that the ampholytic p(AEMA-co-SPMA) polymer could be potentially used for antibiofouling applications and also in applications where salinity is high.

In summary, we present a simple, inexpensive, and nontoxic procedure to prepare an antifouling polyampholytic coating, with physicochemical and antifouling performance similar to that of proper zwitterionic coatings, making it suitable for applications in high salinity such as seawater or physiological conditions.

\section{ASSOCIATED CONTENT}

\section{SI Supporting Information}

The Supporting Information is available free of charge at https://pubs.acs.org/doi/10.1021/acsapm.1c00383.

Data showing degradation of $\mathrm{p}$ (AEMA-co-SPMA) under prolonged UV illumination, FT-IRAS spectra of $p$ (AEMA-co-SPMA) of varying thicknesses, variation of fibrinogen adsorption with $\mathrm{p}$ (AEMA-co-SPMA) layer thicknesses, and details of the XPS analysis with a table showing the elemental composition (PDF)

\section{AUTHOR INFORMATION}

\section{Corresponding Author}

Thomas Ederth - Division of Biophysics and Bioengineering, IFM, Linköping University, SE-581 83 Linköping, Sweden; ○ orcid.org/0000-0002-1639-5735; Email: thomas.ederth@liu.se
Authors
Wetra Yandi - Division of Biophysics and Bioengineering, IFM, Linköping University, SE-581 83 Linköping, Sweden 
Bela Nagy - Division of Biophysics and Bioengineering, IFM, Linköping University, SE-581 83 Linköping, Sweden; (ㄱ) orcid.org/0000-0001-7173-4229

Andreas Skallberg - Division of Molecular Surface Physics and Nanoscience, IFM, Linköping University, SE-581 83 Linköping, Sweden; 이이이.org/0000-0001-7329-7130

Kajsa Uvdal - Division of Molecular Surface Physics and Nanoscience, IFM, Linköping University, SE-581 83 Linköping, Sweden; 다이.org/0000-0002-0314-4291

Ralf Zimmermann - Leibniz Institute of Polymer Research Dresden, Max Bergmann Center of Biomaterials Dresden, 01069 Dresden, Germany; 이이.org/0000-0003-42560754

Bo Liedberg - Division of Biophysics and Bioengineering, IFM, Linköping University, SE-581 83 Linköping, Sweden; Centre for Biomimetic Sensor Science, School of Materials Science and Engineering, Nanyang Technological University, Singapore 637553; 이이이.org/0000-0003-2883-6953

Complete contact information is available at: https://pubs.acs.org/10.1021/acsapm.1c00383

\section{Notes}

The authors declare no competing financial interest.

\section{ACKNOWLEDGMENTS}

We thank Gunnar Cervin and Henrik Pavia for assistance during algal collection at the Sven Lovén Centre for Marine Sciences at Tjärnö, Nelly Rein for running the streaming current measurements, Susann Schmidt for providing the XPS data, and Niclas Solin for discussion. This study was supported by the European Community's Seventh Framework Program FP7/2007-2013 (grant agreement number 237997, SEACOAT). T.E. and B.N. acknowledge financial support from the Swedish Research Council (VR dnr 2014-04004 and 201706696). T.E. and K.U. acknowledge financial support from the Swedish Government Strategic Research Area in Materials Science on Functional Materials at Linköping University (Faculty Grant SFO-Mat-LiU \#2009-00971). K.U. and A.S. acknowledge financial support from the Swedish Research Council (VR grant 621-2013-5357) and Carl Tryggers Stiftelse (CTS 15:507).

\section{REFERENCES}

(1) Ostuni, E.; Chapman, R. G.; Holmlin, R. E.; Takayama, S.; Whitesides, G. M. A survey of structure-property relationships of surfaces that resist the adsorption of protein. Langmuir 2001, 17, 5605-5620.

(2) Chen, S. F.; Jiang, S. Y. A new avenue to nonfouling materials. Adv. Mater. 2008, 20, 335-338.

(3) Laschewsky, A.; Rosenhahn, A. Molecular Design of Zwitterionic Polymer Interfaces: Searching for the Difference. Langmuir 2019, 35, $1056-1071$.

(4) Li, D.; Wei, Q.; Wu, C.; Zhang, X.; Xue, Q.; Zheng, T.; Cao, M. Superhydrophilicity and strong salt-affinity: Zwitterionic polymer grafted surfaces with significant potentials particularly in biological systems. Adv. Colloid Interface Sci. 2020, 278, No. 102141.

(5) Shih, Y.; Venault, A.; Tayo, L. L.; Chen, S. H.; Higuchi, A.; Deratani, A.; Chinnathambi, A.; Alharbi, S. A.; Quemener, D.; Chang, Y. A Zwitterionic-Shielded Carrier with $\mathrm{pH}$-Modulated Reversible Self-Assembly for Gene Transfection. Langmuir 2017, 33, 19141926.

(6) Huang, Z.; Nazifi, S.; Jafari, P.; Karim, A.; Ghasemi, H. Networked Zwitterionic Durable Antibacterial Surfaces. ACS Appl. Bio Mater. 2020, 3, 911-919.
(7) Hu, Y. C.; Liang, B.; Fang, L.; Ma, G. L.; Yang, G.; Zhu, Q.; Chen, S. F.; Ye, X. S. Antifouling Zwitterionic Coating via Electrochemically Mediated Atom Transfer Radical Polymerization on Enzyme-Based Glucose Sensors for Long-Time Stability in 37 degrees C Serum. Langmuir 2016, 32, 11763-11770.

(8) Zang, L.; Zheng, S.; Wang, L.; Ma, J.; Sun, L. Zwitterionic nanogels modified nanofibrous membrane for efficient oil/water separation. J. Membr. Sci. 2020, 612, No. 118379.

(9) Ederth, T.; Lerm, M.; Orihuela, B.; Rittschof, D. Resistance of Zwitterionic Peptide Monolayers to Biofouling. Langmuir 2019, 35, $1818-1827$.

(10) Gao, M.; Gawel, K.; Stokke, B. T. Polyelectrolyte and antipolyelectrolyte effects in swelling of polyampholyte and polyzwitterionic charge balanced and charge offset hydrogels. Eur. Polym. J. 2014, 53, 65-74.

(11) Georgiev, G. S.; Kamenska, E. B.; Vassileva, E. D.; Kamenova, I. P.; Georgieva, V. T.; Iliev, S. B.; Ivanov, I. A. Self-Assembly, Antipolyelectrolyte Effect, and Nonbiofouling Properties of Polyzwitterions. Biomacromolecules 2006, 7, 1329-1334.

(12) Chang, Y.; Shu, S. H.; Shih, Y. J.; Chu, C. W.; Ruaan, R. C.; Chen, W. Y. Hemocompatible Mixed-Charge Copolymer Brushes of Pseudozwitterionic Surfaces Resistant to Nonspecific Plasma Protein Fouling. Langmuir 2010, 26, 3522-3530.

(13) Dobbins, S. C.; McGrath, D. E.; Bernards, M. T. Nonfouling Hydrogels Formed from Charged Monomer Subunits. J. Phys. Chem. B 2012, 116, 14346-14352.

(14) Cao, Z. Q.; Jiang, S. Y. Zwitterionic/mixed-charge polymers as next-generation biomaterials. Abstr. Pap. Am. Chem. S 2010, 240.

(15) Zhang, W.; Yang, Z.; Kaufman, Y.; Bernstein, R. Surface and anti-fouling properties of a polyampholyte hydrogel grafted onto a polyethersulfone membrane. J. Colloid Interface Sci. 2018, 517, 155165.

(16) Leng, C.; Huang, H.; Zhang, K.; Hung, H.-C.; Xu, Y.; Li, Y.; Jiang, S.; Chen, Z. Effect of Surface Hydration on Antifouling Properties of Mixed Charged Polymers. Langmuir 2018, 34, 65386545.

(17) Chou, C.; Syu, S.; Chang, J.-H.; Aimar, P.; Chang, Y. Bioinspired Pseudozwitterionic Hydrogels with Bioactive Enzyme Immobilization via pH-Responsive Regulation. Langmuir 2019, 35, 1909-1918.

(18) Yi, S.; Seo, J.; Lee, J.; Park, J.-S.; Kang, Y. C.; Seo, J.-H. Photoimmobilization of pseudozwitterionic polymers with balanced electrical charge for developing anti-coagulation surfaces. J. Ind. Eng. Chem. 2020, 91, 263-272.

(19) Wu, Y.; Raju, C.; Hou, Z.; Si, Z.; Xu, C.; Pranantyo, D.; Marimuthu, K.; De, P. P.; Ng, O. T.; Pethe, K.; Kang, E.-T.; ChanPark, M. B. Mixed-charge pseudo-zwitterionic copolymer brush as broad spectrum antibiofilm coating. Biomaterials 2021, 273, No. 120794.

(20) Aldred, N.; Li, G.; Gao, Y.; Clare, A. S.; Jiang, S. Modulation of barnacle (Balanus amphitrite Darwin) cyprid settlement behavior by sulfobetaine and carboxybetaine methacrylate polymer coatings. Biofouling 2010, 26, 673-683.

(21) Hibbs, M. R.; Hernandez-Sanchez, B. A.; Daniels, J.; Stafslien, S. J. Polysulfone and polyacrylate-based zwitterionic coatings for the prevention and easy removal of marine biofouling. Biofouling 2015, $31,613-624$

(22) Higaki, Y.; Nishida, J.; Takenaka, A.; Yoshimatsu, R.; Kobayashi, M.; Takahara, A. Versatile inhibition of marine organism settlement by zwitterionic polymer brushes. Polym. J. 2015, 47, 811818

(23) Zhang, Z.; Finlay, J. A.; Wang, L.; Gao, Y.; Callow, J. A.; Callow, M. E.; Jiang, S. Polysulfobetaine-Grafted Surfaces as Environmentally Benign Ultralow Fouling Marine Coatings. Langmuir 2009, 25, 13516-13521.

(24) Quintana, R.; Jańczewski, D.; Vasantha, V. A.; Jana, S.; Lee, S. S. C.; Parra-Velandia, F. J.; Guo, S.; Parthiban, A.; Teo, S. L.-M.; Vancso, G. J. Sulfobetaine-based polymer brushes in marine environment: Is there an effect of the polymerizable group on the 
antifouling performance? Colloids Surf. B: Biointerfaces 2014, 120, $118-124$.

(25) Ventura, C.; Guerin, A. J.; El-Zubir, O.; Ruiz-Sanchez, A. J.; Dixon, L. I.; Reynolds, K. J.; Dale, M. L.; Ferguson, J.; Houlton, A.; Horrocks, B. R.; Clare, A. S.; Fulton, D. A. Marine antifouling performance of polymer coatings incorporating zwitterions. Biofouling 2017, 33, 892-903.

(26) Li, S.; Li, C.; Li, T.; Cheng, J., Polymer photochemistry principles and applications; Fudan University Press: Shanghai, 1993; 110.

(27) Wang, H.; Brown, H. R. Self-Initiated Photopolymerization and Photografting of Acrylic Monomers. Macromol. Rapid Commun. 2004, 25, 1095-1099.

(28) Larsson, A.; Ekblad, T.; Andersson, O.; Liedberg, B. Photografted Poly(ethylene glycol) Matrix for Affinity Interaction Studies. Biomacromolecules 2007, 8, 287-295.

(29) Ekblad, T.; Bergström, G.; Ederth, T.; Conlan, S. L.; Mutton, R.; Clare, A. S.; Wang, S.; Liu, Y.; Zhao, Q.; D’Souza, F.; Donnelly, G. T.; Willemsen, P. R.; Pettitt, M. E.; Callow, M. E.; Callow, J. A.; Liedberg, B. Poly(ethylene glycol)-Containing Hydrogel Surfaces for Antifouling Applications in Marine and Freshwater Environments. Biomacromolecules 2008, 9, 2775-2783.

(30) Tai, F.-I.; Sterner, O.; Andersson, O.; Ekblad, T.; Ederth, T. $\mathrm{pH}$-control of the protein resistance of thin hydrogel gradient films. Soft Matter 2014, 10, 5955-5964.

(31) Tai, F.-I.; Sterner, O.; Andersson, O.; Ekblad, T.; Ederth, T. Interaction Forces on Polyampholytic Hydrogel Gradient Surfaces. ACS Omega 2019, 4, 5670-5681.

(32) Ekblad, T.; Faxälv, L.; Andersson, O.; Wallmark, N.; Larsson, A.; Lindahl, T. L.; Liedberg, B. Patterned Hydrogels for Controlled Platelet Adhesion from Whole Blood and Plasma. Adv. Funct. Mater. 2010, 20, 2396-2403.

(33) Wibisono, Y.; Yandi, W.; Golabi, M.; Nugraha, R.; Cornelissen, E. R.; Kemperman, A. J. B.; Ederth, T.; Nijmeijer, K. Hydrogel-coated feed spacers in two-phase flow cleaning in spiral wound membrane elements: A novel platform for eco-friendly biofouling mitigation. Water Res. 2015, 71, 171-186.

(34) Zimmermann, R.; Osaki, T.; Schweiß, R.; Werner, C. Electrokinetic microslit experiments to analyse the charge formation at solid/liquid interfaces. Microfluid. Nanofluid. 2006, 2, 367-379.

(35) Yandi, W.; Mieszkin, S.; di Fino, A.; Martin-Tanchereau, P.; Callow, M. E.; Callow, J. A.; Tyson, L.; Clare, A. S.; Ederth, T. Charged hydrophilic polymer brushes and their relevance for understanding marine biofouling. Biofouling 2016, 32, 609-625.

(36) Dunér, G.; Thormann, E.; Dedinaite, A. Quartz Crystal Microbalance with Dissipation (QCM-D) studies of the viscoelastic response from a continuously growing grafted polyelectrolyte layer. $J$. Colloid Interface Sci. 2013, 408, 229-234.

(37) Callow, M. E.; Callow, J. A.; Pickett-Heaps, J. D.; Wetherbee, R. Primary adhesion of Enteromorpha (Chlorophyta, Ulvales) propagules: Quantitative settlement studies and video microscopy. J. Phycol. 1997, 33, 938-947.

(38) Starr, R. C.; Zeikus, J. A. Utex - the Culture Collection of Algae at the University-of-Texas at Austin 1993 List of Cultures. J. Phycol. 1993, 29, 1-106.

(39) Jeffrey, S. W.; Humphrey, G. F. New Spectrophotometric Equations for Determining Chlorophylls a, B, C1 and C2 in HigherPlants, Algae and Natural Phytoplankton. Biochem. Physiol. Pflanz. 1975, 167, 191-194.

(40) Zhang, Z.; Zhang, M.; Chen, S.; Horbett, T. A.; Ratner, B. D.; Jiang, S. Blood compatibility of surfaces with superlow protein adsorption. Biomaterials 2008, 29, 4285-4291.

(41) Liu, H.; Ma, Z.; Yang, W.; Pei, X.; Zhou, F. Facile preparation of structured zwitterionic polymer substrate via sub-surface initiated atom transfer radical polymerization and its synergistic marine antifouling investigation. Eur. Polym. J. 2019, 112, 146-152.

(42) Lee, W. J.; Chang, J. G.; Ju, S. P. Hydrogen-Bond Structure at the Interfaces between Water/Poly(methyl methacrylate), Water/ Poly(methacrylic acid), and Water/Poly(2-aminoethylmethacrylamide). Langmuir 2010, 26, 12640-12647.
(43) Kitano, H.; Mori, T.; Takeuchi, Y.; Tada, S.; Gemmei-Ide, M.; Yokoyama, Y.; Tanaka, M. Structure of water incorporated in sulfobetaine polymer films as studied by ATR-FTIR. Macromol. Biosci. 2005, 5, 314-321.

(44) Zimmermann, R.; Dukhin, S. S.; Werner, C.; Duval, J. F. L. On the use of electrokinetics for unraveling charging and structure of soft planar polymer films. Curr. Opin. Colloid Interface Sci. 2013, 18, 8392.

(45) Lyklema, J., Fundamentals of Interface and Colloid Science; Academic Press: London, 1995.

(46) Zhou, Y.; Raphael, R. M. Solution pH Alters Mechanical and Electrical Properties of Phosphatidylcholine Membranes: Relation between Interfacial Electrostatics, Intramembrane Potential, and Bending Elasticity. Biophys. J. 2007, 92, 2451-2462.

(47) Zimmermann, R.; Küttner, D.; Renner, L.; Kaufmann, M.; Zitzmann, J.; Müller, M.; Werner, C. Charging and structure of zwitterionic supported bilayer lipid membranes studied by streaming current measurements, fluorescence microscopy, and attenuated total reflection Fourier transform infrared spectroscopy. Biointerphases 2009, 4, 1-6.

(48) Mary, P.; Bendejacq, D. D.; Labeau, M.-P.; Dupuis, P. Reconciling Low- and High-Salt Solution Behavior of Sulfobetaine Polyzwitterions. J. Phys. Chem. B 2007, 111, 7767-7777.

(49) Guo, S.; Jańczewski, D.; Zhu, X.; Quintana, R.; He, T.; Neoh, K. G. Surface charge control for zwitterionic polymer brushes: Tailoring surface properties to antifouling applications. J. Colloid Interface Sci. 2015, 452, 43-53.

(50) Bismarck, A.; Kumru, M. E.; Springer, J. Characterization of Several Polymer Surfaces by Streaming Potential and Wetting Measurements: Some Reflections on Acid-Base Interactions. J. Colloid Interface Sci. 1999, 217, 377-387.

(51) Schweiss, R.; Welzel, P. B.; Werner, C.; Knoll, W. Dissociation of Surface Functional Groups and Preferential Adsorption of Ions on Self-Assembled Monolayers Assessed by Streaming Potential and Streaming Current Measurements. Langmuir 2001, 17, 4304-4311.

(52) Marinova, K. G.; Alargova, R. G.; Denkov, N. D.; Velev, O. D.; Petsev, D. N.; Ivanov, I. B.; Borwankar, R. P. Charging of Oil-Water Interfaces Due to Spontaneous Adsorption of Hydroxyl Ions. Langmuir 1996, 12, 2045-2051.

(53) Yan, J.; Li, B.; Zhou, F.; Liu, W. Ultraviolet Light-Induced Surface-Initiated Atom-Transfer Radical Polymerization. ACS Macro Lett. 2013, 2, 592-596.

(54) Ooi, Y.; Hobara, D.; Yamamoto, M.; Kakiuchi, T. Ideal Nonideality in Adsorption of 2-Aminoethanethiol and 2-Mercaptoethane Sulfonic Acid To Form Electrostatically Stabilized Binary SelfAssembled Monolayers on $\mathrm{Au}(111)$. Langmuir 2005, 21, 1118511189.

(55) Bauer, S.; Alles, M.; Finlay, J. A.; Callow, J. A.; Callow, M. E.; Rosenhahn, A. Influence of zwitterionic SAMs on protein adsorption and the attachment of algal cells. J. Biomater. Sci., Polym. Ed. 2014, 25, $1530-1539$.

(56) Jhong, J.-F.; Sin, M.-C.; Kung, H.-H.; Chinnathambi, A.; Alharbi, S. A.; Chang, Y. Hemocompatibility of pseudozwitterionic polymer brushes with a systematic well-defined charge-bias control. $J$. Biomater. Sci., Polym. Ed. 2014, 25, 1558-1572.

(57) Venault, A.; Wei, T.-C.; Shih, H.-L.; Yeh, C.-C.; Chinnathambi, A.; Alharbi, S. A.; Carretier, S.; Aimar, P.; Lai, J.-Y.; Chang, Y. Antifouling pseudo-zwitterionic poly(vinylidene fluoride) membranes with efficient mixed-charge surface grafting via glow dielectric barrier discharge plasma-induced copolymerization. J. Membr. Sci. 2016, 516, 13-25.

(58) Patel, R.; Chi, W. S.; Ahn, S. H.; Park, C. H.; Lee, H.-K.; Kim, J. H. Synthesis of poly(vinyl chloride)-g-poly(3-sulfopropyl methacrylate) graft copolymers and their use in pressure retarded osmosis (PRO) membranes. Chem. Eng. J. 2014, 247, 1-8.

(59) Gregurec, D.; Olszyna, M.; Politakos, N.; Yate, L.; Dahne, L.; Moya, S. E. Stability of polyelectrolyte multilayers in oxidizing media: a critical issue for the development of multilayer based membranes for nanofiltration. Colloid Polym. Sci. 2015, 293, 381-388. 
(60) van de Burgt, Y.; Lubberman, E.; Fuller, E. J.; Keene, S. T.; Faria, G. C.; Agarwal, S.; Marinella, M. J.; Alec Talin, A.; Salleo, A. A non-volatile organic electrochemical device as a low-voltage artificial synapse for neuromorphic computing. Nat. Mater. 2017, 16, 414.

(61) Bourg, M.-C.; Badia, A.; Lennox, R. B. Gold-Sulfur Bonding in 2D and 3D Self-Assembled Monolayers: XPS Characterization. J. Phys. Chem. B 2000, 104, 6562-6567.

(62) Yan, Y.; Hao, B.; Wang, X.; Chen, G. Bio-inspired synthesis of titania with polyamine induced morphology and phase transformation at room-temperature: Insight into the role of the protonated amino group. Dalton Trans. 2013, 42, 12179-12184.

(63) Callow, M. E.; Callow, J. E. Marine biofouling: a sticky problem. Biologist (London) 2002, 49, 10-14.

(64) Rosenhahn, A.; Finlay, J. A.; Pettit, M. E.; Ward, A.; Wirges, W.; Gerhard, R.; Callow, M. E.; Grunze, M.; Callow, J. A. Zeta potential of motile spores of the green alga Ulva linza and the influence of electrostatic interactions on spore settlement and adhesion strength. Biointerphases 2009, 4, 7-11.

(65) Ederth, T.; Nygren, P.; Pettitt, M. E.; Östblom, M.; du, C. X.; Broo, K.; Callow, M. E.; Callow, J.; Liedberg, B. Anomalous settlement behavior of Ulva linza zoospores on cationic oligopeptide surfaces. Biofouling 2008, 24, 303-312.

(66) Ederth, T.; Pettitt, M. E.; Nygren, P.; Du, C. X.; Ekblad, T.; Zhou, Y.; Falk, M.; Callow, M. E.; Callow, J. A.; Liedberg, B. Interactions of Zoospores of Ulva linza with Arginine-Rich Oligopeptide Monolayers. Langmuir 2009, 25, 9375-9383.

(67) Park, D.; Finlay, J. A.; Ward, R. J.; Weinman, C. J.; Krishnan, S.; Paik, M.; Sohn, K. E.; Callow, M. E.; Callow, J. A.; Handlin, D. L.; Willis, C. L.; Fischer, D. A.; Angert, E. R.; Kramer, E. J.; Ober, C. K. Antimicrobial Behavior of Semifluorinated-Quaternized Triblock Copolymers against Airborne and Marine Microorganisms. ACS Appl. Mater. Interfaces 2010, 2, 703-711.

(68) Yandi, W.; Mieszkin, S.; Callow, M. E.; Callow, J. A.; Finlay, J. A.; Liedberg, B.; Ederth, T. Antialgal activity of poly(2(dimethylamino)ethyl methacrylate) (PDMAEMA) brushes against the marine alga Ulva. Biofouling 2017, 33, 169-183.

(69) Chen, S.; Yu, F.; Yu, Q.; He, Y.; Jiang, S. Strong Resistance of a Thin Crystalline Layer of Balanced Charged Groups to Protein Adsorption. Langmuir 2006, 22, 8186-8191.

(70) Sponchioni, M.; Capasso Palmiero, U.; Manfredini, N.; Moscatelli, D. RAFT copolymerization of oppositely charged monomers and its use to tailor the composition of nonfouling polyampholytes with an UCST behaviour. React. Chem. Eng. 2019, 4, 436-446. 